\title{
Effective Allocation of Resources in Landform Repair and Reconstruction for Closure - Newmont's Tanami Closure Programme 2005-2008
}

\author{
R. Haymont Newmont Asia Pacific, Australia \\ E. Clements Newmont Asia Pacific, Australia \\ H. Lacy Outback Ecology, Australia
}

\begin{abstract}
Newmont's Tanami mine is in the final stages of a closure process that commenced with a strategic closure assessment of a large series of landforms. This process included waste rock landforms, stockpiles, open cut pits (some backfilled), and tailing storage facilities (in-pit and paddock style). Given the scale and extent of the various project areas, an effective process was required to manage and track resource allocation specific to these areas, and to enable continuous improvement throughout the process. This paper describes the comprehensive and flexible process that was required to deliver the project objectives. Through a case study style presentation, the significant investments made by Newmont in mine closure at Tanami are considered and the principles and learnings gained from this project described and explored.
\end{abstract}

\section{Introduction}

The Tanami mine, located in one of the most remote and inhospitable locations of Australia, has undergone a sustained mine closure programme since 2005, and continues into 2008. The site, situated on Aboriginal freehold land within the Tanami Desert of the Northern Territory, approximately $670 \mathrm{~km}$ west from Alice Springs, was mined and processed for gold from 1900 to 2004. The site comprises twenty open pits, five backfilled pits, twenty waste rock landforms, ten in-pit tailings storage facilities, two above ground tailing storage facilities, a mill and a camp. The mine site is in the final phase of closure, following a lengthy period of closure planning, investigation work and earthworks.

Large mine closures throughout the world frequently and significantly exceeded the cost estimates and budgets allocated to the closure process because of a number of factors including poor estimation, inadequate planning and investigation, and poor cost and resource control. Frequently the use of equipment specific to mining and mine engineering applied to mine rehabilitation activities results in sub-optimal outcomes.

Had the Tanami mine closure process not had good quality planning, implementation processes, appropriate review, regular adjustments to design, and utilised a mining fleet rather than specialist rehabilitation earthmovers, it is certain that the project would now be well beyond the original budgets. As it is the project is on track to perform within $10 \%$ of the original estimates.

\section{Closure planning and investigation process}

Central to any successful activity is the gathering of information and the assimilation, verification and application of that knowledge into robust plans. This process must commence well before the closure of landforms and tailings facilities commences, and importantly it must continue during, throughout and after the process. The facilitation and action of continuous improvement to facilitate the gathering of knowledge on varying working conditions, materials encountered and their management, approaches to different challenges and to understanding the performance of adopted designs, is necessary so that refinements and adjustments can be made on a continuous basis. This approach promotes the generation of quality outcomes in final landform work, minimises risks and ongoing management in the long term. 
Newmont in Australia has a standardised process and documentation structure for mine closure, which captures essential information such as:

- Conditions and commitments.

- Completion criteria.

- Liability estimation.

- Materials characterisation.

- Hydrology.

- Geotechnical considerations.

- Rehabilitation work plans.

- Risk assessment and management.

- Stakeholder participation.

- Post closure performance monitoring.

- Closure management systems.

This system ensures that the key aspects of closure are captured. It also, however, allows for individual needs and attributes of a particular site to influence and take precedence over the constraints of a system - and its potential inflexibility. In order to complete such a plan, a range of investigations are required to ensure that sufficient understanding of the key attributes of the site are understood, to permit robust designs to be developed.

Designs are developed as a collaborative process with Newmont regional and site based personnel, experienced consultants and earthworks contractors, all contributing to the final design outcome for each individual landform encountered. External stakeholders also play a significant role in influencing the final outcomes. Once the design principles are established, activities are specified in detail via a work instruction process which breaks activities in each project area into tasks, and provides directions which are developed and provided to members of the project team before being issued to the contractor for implementation.

\section{Waste rock landforms}

One of the challenges of management of a large project, which has rehabilitation of different ages and technical approaches, is that it is easy to disregard or recommend the complete rework of facilities to the latest design approach or standard. However, this is sometimes the only practical solution when there has clearly been inadequate performance, and monitoring data suggests that the facility is unlikely to ever realise a satisfactory standard of performance.

It is frequently the case however, that waste landforms can be made to meet acceptable standards with a review of various aspects of their performance and re-invigoration of landforms that are not performing satisfactorily is possible. Drainage control is often a key feature that causes performance failure and which must be investigated. Often, older style waste rock landforms at Tanami had been designed with berms which, having concentrated water at low points led to erosion in a number of locations. Often these failures can be traced to mismanagement at the top of "the catchment" e.g. the top of the landform and its batters and slopes. If there was insufficient attention given to water control, as opposed to an appropriate policy to manage water based on the type of material contained within the landform, failures are inevitable. Poor drainage design on the top of the landform during the construction process will generally lead to failures.

If berms were not adequate for the intended function, i.e. to move water to drainage structures, were not level, were inadequate to cope with the erosive effect of flowing water, were insufficiently engineered, or did not have outer perimeter drainage bunds, erosion will rapidly make it appear that the design intent of the facility has failed, when what in fact, has happened, is that the initial construction methodologies were not based on a clear policy. The vital question "what do you wish to achieve in waste landform construction?" and developing a water management design policy based on the response to this question taking into 
consideration the waste material, the environment, the closure criteria and then remaining faithful to the design policy is required.

Often rather than reworking an entire landform, a targeted programme to correct earlier construction failures can salvage a landform and make it meet the expectations of stakeholders. Removing berms, and moving to concave slope forms with armour applied to dispersive and erodible wastes is sometimes necessary to achieve a design objective.

Another important decision is to determine if erosion features are armouring and stabilising, or active and increasing. Although one can use very sophisticated monitoring to establish this, experienced personnel can also generally make a valid judgement and, rather than delay the process of proceeding with repair and completion works, and endlessly monitor, it is possible to make a determination and fix the erosion features which are considered active or represent a risk. At the same time one can allow those that are self stabilising to evolve - if they are having little off-site impact. The landform will no doubt be monitored for some time into the future to identify any failures of this approach, and it is inevitable over the course of time that there will be failures driven by extenuating circumstances.

\section{Stockpiles}

Stockpiles are frequently dumped in such a way that they are more expensive to rehabilitate than is necessary. They are often dumped with steep angles of repose slopes, with no berms, meaning that significant reprofiling is required. Naturally if there is any reasonable chance that the material will processed it should be left in situ, but stabilised and revegetated.

\section{Tailings storage facilities (TSFs)}

The Tanami operations developed ten in-pit TSFs and two above-ground TSFs.

\subsection{In-pit TSFs}

The Tanami mine had utilised ten voids for in-pit tailings storage. In some cases the surfaces were well compacted and easily rehabilitated, in others operational approaches meant that the material was very unconsolidated and difficult to close. Side tipper trucks to transport material to these covers and graders were used to good effect on the consolidated facilities, but on unconsolidated facilities end tipping become expensive, and it was clear that the bulk of the cover material was ending up below the surface of the tailings. A long reach excavator was specifically deployed for the application of cover layers, and has made a considerable impact on costs and the rate of progress.

\subsection{Above-ground TSFs}

The process for closure of the Three Cell TSF was largely a staged process that ensures an appropriate and acceptable decommissioning procedure is followed. This approach involves a logical sequence of:

- Stakeholder discussions, site visit and document review.

- Sampling, investigations and research are required to define tailings and rehabilitation materials. Then in association with other specialist sub-consultants (where required) closure issues are resolved.

- Preparation of a draft TSF decommissioning plan for submission to regulators.

- Decommissioning of the TSF and preparation of a "as built" and final TSF decommissioning plan.

- Monitoring and sign-off.

Review of literature related to the Three Cell TSF provided foundation information and guided decommissioning toward an appropriate closure strategy. This included a review of conditions and commitments related to the TSF to ensure compliance with regulations. Furthermore review of various geotechnical, hydrological, geochemical and environmental information provided a solid understanding of the TSF. It exposed gaps in information, which were primarily related to geochemical properties of the 
tailings, water balance modelling and physiochemical properties of regolith cover materials. This highlighted the extent of possible migration and upward movement of salt into cover profiles, the most appropriate soil cover profile for plant growth and the most suitable plant species for the environment and conditions of the TSF. To resolve some of these unknowns, investigations were required to gain a greater level of understanding. For example, a tailings trial was established on the upper surface of the Three Cell TSF to determine the most appropriate cover profile for plant establishment and growth. The results from this trial will provide valuable information that can be extended to other tailings facilities in the Tanami area, thus maximising the investment.

A draft decommissioning plan for the facility was presented to regulators and the CLC and has been progressively implemented over the past 12 months. The two biggest challenges for the design were the cover design and the drainage design. There were some significant cost differences associated with alternate approaches and one of the most critical decisions of the project was to question the assumption that the tailings were to some degree phytotoxic due to salinity. Extensive testing of the material and field trials demonstrated that the main growing strata of the tailings were in fact quite benign. The original advisors to the project had specified a store and release cover. It was determined that this was unnecessary and that an infiltrating cover would realise better plant establishment and water management outcomes. This was a better environmental outcome and a much more cost effective outcome. Store and release covers in arid areas on TSFs, waste rock landforms, stockpiles and dumps, should be questioned as they are often automatically applied without a good understanding of the context in which they are placed.

\section{Open pits}

In most cases the water in open pits at the Tanami is either fresh or brackish. Although it is likely that there will be some concentration of dissolved solids over time with evaporation, where possible local drainage has been directed into pits to maintain water quality, and where there is recharge above the local groundwater table, a recharge of good quality water into the surrounding aquifer occurs. This has proven quite successful in the aftermath of exceptional rain events.

\section{$7 \quad$ Resource and cost tracking system}

The site coordinator of the Tanami Closure Project developed a detailed cost tracking process known as Claris which references the work instructions developed within the closure plan and allows the costs of closure activities to be tracked on a task by task, work type by work type and machine by machine basis. This allows detailed cost and performance reporting and highlights the differences in estimates and actuals, these differences can then be reduced by using actual numbers going forward.

\section{Conclusions}

In a large project where there is a significant number and diversity of landforms and facilities, good control on the application of resources is essential. Some of the key things to ensure are that one discipline does not overpower other disciplines to the detriment of the overall project by skewing designs in favour of the preferences of specific discipline advisors or consultants.

Using the machinery that is at hand to save mobilisation and demobilisation can be a mistake if the machinery is large and not particularly nimble, as with many surface mining fleets. It may be better to demobilise this machinery and mobilise in machinery that can advance the project at a more measured rate and apply material more precisely than the larger machinery. The quality and capacities of the operators of the machinery are critical in maximising cost efficiency and avoiding budget overruns.

Individual planning per facility rather than a "one approach fits all" style of response means that the performance of each facility, or each part of each facility, can be taken on its merits and hence where repair and intervention work can be very targeted and specific - this can be achieved. The capacity of the project to respond to changes in circumstances is essential, such as when borrow material types being uncovered change through the profile of a source, when there are large climatic events or when the application of designs being applied, however cherished, demonstrate flaws. 